Authors have nothing to disclose with regard to commercial support.

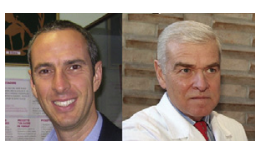

\section{VALVE-SPARING REPAIR DURING REPAIR OF TETRALOGY OF FALLOT: SURGICAL CONTROVERSIES}

\section{To the Editor:}

The recently published study of Hofferberth and colleagues ${ }^{1}$ outlines that a pulmonary valve (PV)-sparing tetralogy of Fallot (ToF) repair by means of an intraoperative balloon dilation (IBD) is associated with the development of a progressive PV insufficiency and right ventricle (RV) dilation. Hofferberth and colleagues ${ }^{1}$ conclude that $\mathrm{PV}$-sparing with IBD is not a suitable long-term solution to preserve $\mathrm{PV}$ function in patients with TOF.

According to our recent unpublished results, at a median follow-up of 4.1 years (interquartile range, 1.9-5.4 years), none of our patients who underwent PV-sparing ToF repair required further surgical or hemodynamic interventions. The median RV outflow tract gradient was $20 \mathrm{~mm} \mathrm{Hg}$ (interquartile range, $15-25 \mathrm{~mm} \mathrm{Hg}$ ), and in $75 \%$ of the patients, there was either no residual PV regurgitation or only mild residual PV regurgitation.

We believe that our treated population of young infants (most of them $<4$ months of age) in conjunction with different surgical repair techniques, which included an extensive transpulmonary and transatrial muscle band resection up to the PV annulus and PV dilatation and reconstruction, may have contributed to the avoidance of late RV outflow tract recurrence from residual RV outflow tract obstruction, as seen in the study of Hofferberth and colleagues. ${ }^{1}$ In addition, our midterm follow-up data show that RV function was significantly better preserved in a group of patients with TOF treated by IBD and valvesparing repair than in a matched cohort of patients undergoing a transannular patch repair. ${ }^{2,3}$

\footnotetext{
The Editor welcomes submissions for possible publication in the Letters to the Editor section that consist of commentary on an article published in the Journal or other relevant issues. Authors should: • Include no more than 500 words of text, three authors, and five references. • Type with double-spacing. • See http://jtcs.ctsnetjournals.org/ misc/ifora.shtml for detailed submission instructions. • Submit the letter electronically via jtcvs.editorialmanager.com. Letters commenting on an article published in the JTCVS will be considered if they are received within 6 weeks of the time the article was published. Authors of the article being commented on will be given an opportunity of offer a timely response ( 2 weeks) to the letter. Authors of letters will be notified that the letter has been received. Unpublished letters cannot be returned.
}

With the concept in mind of preserving the PV function, we learned to avoid the use of oversized balloons (according to the calculated normal PV annulus) during intraoperative PV dilatation. Oversized balloons can lead to tears and partial leaflet avulsions, which are sometimes difficult to repair, and they therefore can jeopardize the postintervention PV function. ${ }^{4}$

We are in agreement with Hofferberth and colleagues' conclusions $^{1}$ that IBD, even in association with simple PV plasty maneuvers, is not always effective by itself in preserving $\mathrm{PV}$ function during repair. This is especially true for patients with more severe forms ( $\mathrm{PV} z$ score $<-3$ ), in whom the PV leaflets are usually damaged or the commissures eventually split apart as a result of annular dilation.

We have found that in severe forms of TOF, more complex additional surgical maneuvers on the PV are mandatory for achieving PV competence after IBD. The recent introduction of a delamination plasty technique, ${ }^{4,5}$ which increases the leaflets' coaptation area, allowed us to extend further the applicability of valvesparing repair after IBD. We have now learned how to treat more severe forms, including also unicuspid PVs, by the re-creation of 1 or more commissures for resuspending the delaminated leaflets' tissue. A longer follow-up is still needed to evaluate the efficacy of our surgical technique.

Vladimiro L. Vida, $M D, P h D$

Giovanni Stellin, $M D$

Department of Cardiac, Thoracic, and Vascular Sciences Pediatric and Congenital Cardiac Surgery Unit University of Padua Padua, Italy

\section{References}

1. Hofferberth SC, Nathan M, Marx GR, Lu M, Sleeper L, Marshall AC, et al. Valvesparing repair with intraoperative balloon dilation in tetralogy of Fallot: midterm results and therapeutic implications. J Thorac Cardiovasc Surg. 2018;155: 1163-73.e4.

2. Vida VL, Guariento A, Castaldi B, Sambugaro M, Padalino MA, Milanesi O, et al Evolving strategies for preserving the pulmonary valve during early repair of tetralogy of Fallot: mid-term results. J Thorac Cardiovasc Surg. 2014;147: 687-94; discussion 694-6.

3. Vida VL, Angelini A, Guariento A, Frescura C, Fedrigo M, Padalino M, et al. Preserving the pulmonary valve during early repair of tetralogy of Fallot: anatomic substrates and surgical strategies. J Thorac Cardiovasc Surg. 2015;149: 1358-63.e1.

4. Vida VL, Padalino MA, Maschietto N, Biffanti R, Anderson RH, Milanesi O, et al The balloon dilation of the pulmonary valve during early repair of tetralogy of Fallot. Catheter Cardiovasc Interv. 2012;80:915-21.

5. Vida VL, Zucchetta F, Stellin G. Pulmonary valve-sparing techniques during repair of tetralogy of Fallot: the delamination plasty. J Thorac Cardiovasc Surg. 2016;151:1757-8.

https://doi.org/10.1016/j.jtcvs.2018.02.114 